\title{
ESTILOS
}

DOI:https://doi.org/10.11606/issn.1981-1624.v26i1 p4-16.

\section{Dossiê \\ Corpos estranhos ou não-corpos? Reflexões sobre a participação do corpo no ensino não presencial}

\author{
Cristiana Carneiro; Larissa Costa Beber Scherer
}

Resumo. O presente artigo se propõe a tecer uma reflexão sobre a participação do corpo no ensino não presencial. Partindo da premissa de que o corpo é pulsional, e que a relação professor-aluno se fará a partir das marcas desse encontro/desencontro entre corpos, interroga as possíveis incidências da não presença física no ensino remoto. Discutindo a sexualidade infantil como pano de fundo da relação adulto-criança e a alteridade que ela convoca, situa a estranheza como fator de potência e impotência no inédito trabalho não presencial que a pandemia impôs realizar.

Palavras chave: psicanálise; educação; corpo pulsional; relação professor-aluno; ensino remoto.

\section{¿Cuerpos extraños o no cuerpos? Reflexiones sobre la participación del cuerpo en la docencia no presencial}

Resumen. Este artículo propone reflexionar sobre la participación del cuerpo en la docencia extraescolar. Partiendo de la premisa de que el cuerpo es pulsional, y que la relación entre docente y alumno se basará en las marcas de este encuentro/desajuste entre cuerpos, se cuestiona las posibles incidencias de la no presencia física en la educación a distancia. Discutir la sexualidad infantil como trasfondo de la relación adulto-niño y la alteridad que exige, sitúa la extrañeza como factor de poder e impotencia en el inédito trabajo no presencial que impuso la pandemia.

Palabras clave: psicoanálisis; educación; cuerpo pulsional; relación profesor-alumno; enseñanza remota.

\section{Foreign bodies or non-bodies? Reflections on the participation of the body in non- classroom teaching}

\begin{abstract}
This article proposes to reflect on the participation of the body in non-classroom teaching. Starting from the premise that the body is instinctive, and that the relationship between teacher and student will be based on the marks of this encounter/mismatch between bodies, it questions the possible incidences of physical non-presence in remote education. Discussing child sexuality as a background for the adult-child relationship and the otherness
\end{abstract}

\footnotetext{
* Professora Associada da Faculdade de Educação e do Programa de Pós-graduação em Psicologia da Universidade Federal do Rio de Janeiro, Rio de Janeiro, RJ, Brasil. E-mail: cristianacarneiro13@gmail.com

** Psicanalista. Doutoranda em Psicologia pela Universidade Federal do Rio de Janeiro, Rio de Janeiro, RJ, Brasil.

E-mail: larissascherer70@gmail.com
} 
it calls for, situates strangeness as a power and impotence factor in the unprecedented non-face-to-face work that the pandemic imposed.

Keywords: psychoanalysis; education; instinctive body; teacher-student relationship; remote teaching.

\section{Corps étrangers ou non-corps? Réflexions sur la participation du corps à l'enseignement hors classe}

Résumé. Cet article propose de réfléchir sur la participation du corps à l'enseignement hors classe. Partant du principe que le corps est pulsionnel, et que la relation enseignant-élève sera basée sur les marques de cette rencontre/discordance entre les corps, elle interroge les incidences possibles de la non-présence physique dans l'enseignement à distance. Discuter de la sexualité des enfants comme arrière-plan de la relation adulte-enfant et de l'altérité qu'elle appelle, situe l'étrangeté comme facteur de pouvoir et d'impuissance dans le travail sans précédent sans face à face que la pandémie a imposé.

Mots-clés: psychanalyse; éducation; corps pulsionnel; relation enseignant-élève; enseignement à distance.

Tive um sonho horrível. Estávamos meus companheiros e eu na escola. Vinham uns maus e obrigavam-nos a tomar um líquido para diminuir. Um liquidozinho para diminuir-nos, para que entrássemos nas aulas, porque nossos corpos eram grandes para entrar nas aulas. Quando o tomávamos, as cabeças não diminuíam, mas os corpos ficavam achatados como de papel... Como cadernos! (Fernández, 1991, p. 63)

$\mathrm{O}$

pesadelo de Maria Sol, criança de nove anos, apontaria, segundo Fernández (1991), para o apelo que a escola faz estritamente ao cérebro: crianças sentadas e atadas às mesas e cadeiras. Priorizando a imobilização dos alunos entre quatro paredes e um certo regime de atenção, a escola parece frequentemente "achatar" as crianças, opondo-se à mobilidade criativa dos corpos.

Em pesquisa realizada com crianças e adolescentes, pudemos ouvir que a chatice da escola se deve também a ela ser aprisionante. Como nos disse um adolescente que circulava livremente no seu bairro, mas se sentia trancado na escola: "Mas eu to falando! E eu também não gosto de lá porque lá é trancado" (Coutinho, Carneiro \& Salgueiro, 2018). Justamente o não gostar se referindo ao modelo espacial da escola, ao não poder entrar e sair como quiser, à obrigação de ficar sentado no mesmo lugar...

Apesar desse limite que o espaço escolar impõe, o confinamento forçado da pandemia fez com que pudéssemos ouvir sobre algo bastante diferente das crianças e adolescentes: uma saudade da instituição escola e seus espaços. Nesse sentido, ao mesmo tempo em que o formato de ensino presencial então, muitas vezes, corrobora para uma não expansão das experimentações corporais e trocas, oferece também várias possibilidades de transgressão desse mesmo formato. Basta observarmos o horário do recreio, o empurrão nos corredores, o arfar da correria nas escadas. Como nos disse um menino de dez anos sobre o que preferia na escola: "Bom na hora de brincar... tem muita brincadeira, ai, ai a gente inventa nova, tipo a corda de pular a gente vai, a gente inventou rasteira" (Coutinho, Carneiro \& Salgueiro, 2018). Ele nos indica, nessa fala, que a escola também é espaço de criação e de dar rasteira no colega. Em uma pesquisa recente sobre o ensino não presencial durante a pandemia, Lima (2020) relata que as 
crianças disseram sentir falta de andar no espaço físico da escola e se encontrar com colegas e professores.

Dessa forma, o ambiente escolar se oferece não apenas como espaço da regra e do ordenamento mas, também, lócus de rompimento com o estabelecido e de trocas afetivas que o transformam em um espaço vivo. A escola torna-se um lugar de corpos pulsantes. Podemos, por exemplo, ver essa vivacidade através das manifestações de agressividade demonstradas pelas crianças, como nos indicou o estudante que dá rasteiras e, também, pelo amor expresso nos coleguismos. Essas manifestações indicam como a escola se torna palco privilegiado para o exercício da sexualidade infantil, condição essa que, muitas vezes, desestabiliza o suposto controle pretendido pelos educadores, mas também produz efeitos que potencializam o lugar de transmissão exercido pelo professor.

Como nos lembra Freud (1905/1987), a sexualidade exibe componentes que envolvem, desde o início, pessoas como objetos libidinais. Ele nos alertou quanto às pulsões escopofílicas, de exibicionismo e de crueldade presentes na infância, as quais se relacionam com a vida genital mais tarde, sendo observadas na infância de forma independente, distintas inicialmente da atividade sexual genital. Nesse sentido, podemos também relacionar as manifestações agressivas evidenciadas na infância ao que é próprio à sexualidade infantil e refletir sobre os efeitos da identificação e percepção das mesmas pelos educadores e pares. Se é no palco vivo de um espaço de mobilidades e imobilidades, circulação de diversos afetos, que o educador constrói suas particulares formas de leituras do outro-aluno para modular sua relação com ele, como o fazer a partir da tela?

De modo bastante distinto e inédito, a pandemia trouxe o ensino literalmente para dentro de casa. Não há mais o pátio, a escada e a correria. O corpo não aparece por inteiro na tela, o olhar e a modulação da voz são muito diferentes quando na presença face a face. Pensar essas transformações espaço-temporais contemporâneas é pensar no sujeito, justamente porque, se há transformações no espaço físico material, há transformações também no espaço mental, das representações, que se inter-relacionam e se superpõem (Soja,1993). Como pensar essa abrupta anulação do encontro corpo a corpo nas relações professor-aluno? Haveria algo nesse novo formato "(...) que modifica a forma de considerarmos a presença real, ou seja, aquela que depende do suporte 'corporal'"(Voltolini, 2006, p. 3)?

Longe de trazer uma resposta mais definitiva a esse questionamento, o presente texto propõe alguns eixos de reflexão sobre esse agora que nos ultrapassa e nos convoca a criar formas menos adoecedoras de estar juntos.

\section{O corpo imagem na tela}

Os estudos sobre a relação mediada pela tela não são recentes. Antes da virada do milênio, grandes pensadores já se perguntavam sobre os efeitos na produção de subjetividades que a nova relação com a imagem prenunciava.

A relação com a imagem apontava para um agora mais espacial do que qualquer realidade anteriormente vivida, o que significava dizer que o tempo presente não se encontravapredominantemente inserido em uma realidade de antes e depois (Jameson, 1991). $\mathrm{O}$ aspecto tridimensional do tempo - passado, presente e futuro - parecia esmorecido diante da supremacia de um presente eternizado e exuberante. Essa modificação no registro da temporalidade alterou amplamente a narrativa, corroborando, como bem enunciou a Escola de 
Frankfurt, para o fim das grandes narrativas. A nova forma de narrar no contemporâneo, proposta pela lógica imagética, passou a dispensar a sequência temporal. Nesse sentido, para entender a imagem, suprime-se o antes, o agora e o depois, nos quais a própria sucessão conferiria a significação; pelo contrário, é preciso produzir sentido a partir de flashes de imagens pouco relacionados entre si. Isso significa dizer que, no mundo contemporâneo, mediado por imagens, instalou-se uma nova forma de comunicação. A fragmentação imagética ganhou impulso com a velocidade de sucessão das imagens, modificando substancialmente a duração, a permanência. (Carneiro, 2002).

Para Rushkoff (1999), a grande e radical mudança na virada do milênio foi justamente o nível de complexidade da vida, incrementado pela tecnologia e pela centralidade da imagem no cotidiano. Essa complexidade, a que o autor chama caos, exige dos sujeitos uma nova forma de processamento de informações, mais rápida, mais adaptativa. Esse ritmo frenético de ideias exige uma substancial mudança em relação à nossa capacidade de prestar atenção. A atenção se fragmenta em uma multiplicidade de atividades. Nesse sentido, mais do que uma atenção centrada em um mesmo ponto durante um longo período de tempo, a complexidade das imagens exige atenção simultânea em objetos diferentes que mudam com maior velocidade.

Dessa forma, se está existindo uma mudança em relação à capacidade de concentração - e é digno de nota que os adolescentes e crianças não estão conseguindo manter o foco por muito tempo- e, portanto, se estamos assistindo a um encurtamento da duração atencional, também identificamos um alargamento da possibilidade de atividades concomitantes (Rushkoff, 1999). Ou seja, a duração está diminuindo, mas a velocidade da variação da atenção está aumentando consideravelmente.

O hiato entre as imagens, a ausência de sentido, não precisa mais ser explicado linearmente. A nova linguagem imagética que dispensa a compreensibilidade baseada na sucessão, na continuidade, pode ser muito mais veloz, em vista de que o tempo gasto na compreensão da sequência - o debruçar-se em uma compreensão que tem que levar em conta um antes e um depois - pode ser abolido, e o sentido estar mais contido apenas na imagem; o que se vê já fornece o sentido, de uma maneira muito mais imediata, sem precisar de um desdobramento reflexivo. Nessa direção, a linguagem da imagem visual “(...) suspende as restrições de tempo características do raciocínio linear para permitir uma disseminação mais rápida de ideias e dados (...)" (Rushkoff,1999, p. 54).

Chamando a atenção para o fato de que as crianças parecem em um processo hipnótico quando em frente à tela, Voltolini (2006) aponta que a virtualidade apaga o contato com a dimensão temporal, que é justamente aquela que se evidencia na dimensão transferencial. Significa dizer que, nesse modelo hipnótico, a dimensão do laço com o outro e sua própria existência ficam questionados.

No entanto, partindo do pressuposto de que a nova relação com a imagem é irreversível não imaginamos mais a vida sema tela -, é importante pensarmos que essa lógica não fica restrita aos meios de comunicação, mas se expande, havendo "(...) portanto uma dimensão oculta da revolução das comunicações que afeta a duração, o tempo vivido de nossas sociedades" (Virilio,1993, p. 106), fazendo com que o tempo que vivemos passe a ser interpretado também de uma maneira diferente. 
O novo relacionamento apontado por Virilio (1993), a interface com a tela ${ }^{1}$ ao acoplar observador e observado, altera também a distância sujeito/objeto no espaço e no tempo. Em primeiro lugar, é importante ressaltar que, antes, o objeto possuía, na relação com o sujeito, uma proximidade maior, o que poderíamos chamar de existência material, palpável. A partir do momento em que o objeto passa a ser imagem, ele altera a relação com a percepção real, porque pode ter sua grandeza aumentada, diminuída, sua cor modificada, sua profundidade considerada ou não. $\mathrm{O}$ acesso a ele pode se dar apenas pelo simples acionamento de um botão: não precisamos efetuar um deslocamento espacial até o objeto. Os limites objetivos, como tempo e espaço por exemplo, ficam amplamente alterados nessa nova relação.

Nessa supressão da nitidez dos limites, o próximo e o distante deixam de ser categorias evidentes de oposição, pois o distante pode ficar muito próximo na tela, assim como o próximo pode, por meio da imagem, adquirir diferentes distâncias. A referência opositiva perde função para uma maleabilidade que tudo pode. Esse "espaço-tempo tecnológico" (Virilio,1993, p. 10) prescinde das oposições entre os dias e as noites, ao calendário solar da astronomia, podendo ser bem expresso por "um falso dia eletrônico", em que o calendário pode se compor apenas por comutações de informações sem qualquer relação com o tempo real. Esse achatamento do tempo e do espaço na tela causa uma indiferenciação das posições, pois

se o espaço é aquilo que impede que tudo esteja no mesmo lugar, este confinamento brusco faz com que tudo, absolutamente tudo, retorne a este lugar, a esta localização sem localização ..., o esgotamento do relevo natural e das distâncias de tempo achata toda localização e posição (Virilio,1993, p. 13).

O achatamento tempo-espaço faz com que a dimensão, que vem de "dimensus: medida" (Virilio,1993, p. 42), esmoreça-se na sua função de separação entre observado e observante, porque a velocidade também abole a distância entre as dimensões. Isso significa dizer que a velocidade pungente da imagem faz com que o imediato seja o perceptível, e o mediato - o trajeto -, imperceptível. Nesse sentido, essa nova lógica contemporânea ressalta o "esquecimento do "ser do trajeto"" (Virilio, 1993, p. 107), e instaura o imperativo do imediato, do agora. Isso não quer dizer que o antes e o depois deixem de ser considerados; porém, eles o são apenas como imediatamente antes e depois, de tal forma que a relevância, a intensidade do presente, suplante qualquer outro tempo, delineando, assim, um "presente intensivo, fruto da velocidade limite das ondas eletromagnéticas, que não mais se inscreve no tempo cronológico do passado/presente/futuro, mas antes no tempo cronoscópico: subexposto/exposto/superexposto" (Virilio,1993, p. 110), que se refere justamente à exposição do presente a esse antes e depois imediato.

Retomando essa discussão mais especificamente no campo da subjetividade, Birman (2012) também vai ressaltar as modificações contemporâneas de tempo e espaço e seus impactos no psiquismo. Interessado em pensar nas formas comoo mal-estar vem se expressando em nossos tempos, vai nos dizer que, se antes havia uma articulação maior entre mal-estar e sofrimento (Birman, 2001), na atualidade assistimos ao predomínio do binômio mal-estar e dor. Essa mudança estaria ligada justamente ao predomínio do espaço na constituição subjetiva, em queo imediato estaria alinhado a certo empobrecimento simbólico e interpretativo. A dor como forma atual de mal-estar denunciaria uma modalidade subjetiva mais centrada em si mesma, menos narrativa e mais diretamente atuada. De outro modo, o sofrimento pressuporia certa história,

\footnotetext{
1“'A interface delinearia uma nova 'superfície' que anularia a separação clássica de posição, de instante ou de objeto, assim como a tradicional divisão do espaço em dimensões físicas, em benefício de uma configuração instantânea, ou quase, em que o observador e o observado são bruscamente acoplados" (Virilio,1993, p. 39).
} 
pois "se a dor evidencia uma posição solipsista do sujeitoeo seu fechamento em face do outro, o sofrimento seria algode ordem alteritária que pressuporia o apelo e a demandaendereçada ao outro" (Birman, 2012, p. 9). Assim, para esse autor, as mudanças espaço-temporais que vimos acontecer a partir do século passado e que se intensificam no momento atual redundam em solipsismo, empobrecimento simbólico e, sobretudo, diminuição acentuada da dimensão alteritária. Esse último aspecto foi bastante discutido por Lebrun (2008), que nos mostrou diversas consequências da nova forma de viver

juntos sem outro. Na educação, por exemplo, a diminuição da dimensão alteritária poderia ser vista por uma deslegitimação social da autoridade do professor. Segundo o autor, os professores teriam que construir sozinhos seus lugares de autoridade, precisando ser amados para serem aprovados por seus alunos, já que o mundo social não reconhece mais a legitimidade da autoridade do professor.

Toda essa discussão sobre a relação espaço-tempo parece absolutamente relançada pelas contingências da pandemia da COVID-19 em 2020. Reis (2020) descreve essa nova realidade do mundo pandêmico, dizendo que é contrastante a intensidade do veloz contato virtual em relação ao desalento da paralisia do confinamento,em que"a sensação de velocidade deixou de ser uma característica do corpo em movimento e passou para os ecrãs da televisão e dos monitores do smartphone e do computador. A velocidade das pernas deslocou-se para a ansiedade óculo-manual dos teclados" (Reis, 2020, p.69). Lima (2020) cita em sua pesquisa o incômodo de uma menina de dez anos com as aulas online:"eu não sei se o professor está me olhando". Contudo, importaaqui ressaltar que essas mudanças não apenas causaram mal-estar, mas há também relatos tanto de alunos como de professores de que, por exemplo, o não deslocamento permitiu a eles novos afazeres prazerosos (Lima, 2020).

Se a relação com a imagem e a tela não é nova, é novíssima a forma que ela comparece nas relações escolares deste ano. Não se trata de educação a distância, mas de uma escola que espacialmente deixou de existir como experiência concreta para crianças e adolescentes, passando a se alojar, mais ou menos, no espaço da casa e da tela. Como pensar na relação observado e observante no ensino remoto que a quarentena impôs? Diante de corpos reduzidos e achatados, que muitas vezes se representam só por imagens de cabeças, o educador não estará isento da necessidade de produzir um sentido para aquela relação/não relação que ali se produz. Justamente porque é essa produção de sentido que servirá de bússola para a transmissão, já que essa última é sempre relacional. Se o aluno parece ter sono, por exemplo, continua-se falando no mesmo tom? Pela tela, essas modulações demonstradas corporalmente parecem ficar suprimidas. Se seguirmos a indicação de Virilio (1993) de que o achatamento tempo-espaço diminui a função de separação entre observado e observante, ou a indicação de Birman (2012) de que a alteridade está menos presente no modelo mais espacializado de psiquismo dos tempos atuais, podemos hipotetizar que o corpo plano da tela poderia diminuir os subsídios do educador para a interpretação do outro na cena de transmissão? Em que medida podemos considerar a imagem plana de fragmentos do corpo que aparece na tela como um corpo?

\section{Corpo e sexualidade}

Os estudos sobre o corpo na educação são vastos e englobam vários aspectos, sobretudo o ensino e a aprendizagem. Em uma pesquisa de estado da arte sobre corpo e educação, Bezerra e Moreira (2013) puderam afirmar que as mudanças tecnológicas impulsionaram a produção da 
temática; no entanto, ela ainda não é suficientemente explorada, apresentando uma concentração na área da Educação Física. Para os autores, um “(...) ponto importante de confluência entre os estudos é a preocupação dos autores em debater a questão da fragmentação do corpo após a Modernidade, se estendendo para a Contemporaneidade e ganhando força no processo educativo escolar de formação dos seres humanos" (Bezerra e Moreira, 2013, p. 7). Aqui, a crítica se estende a certo reducionismo do corpo, em quea leitura da racionalidade parece suplantar outras chaves de compreensão. Tal perspectiva racionalista aparece minimizada nos estudos psicanalíticos, justamente porque há no próprio arcabouço teórico da psicanálise um lugar de centralidade para aquilo que está fora do domínio da razão: o inconsciente e a pulsão. Esses dois conceitos convergem para uma compreensão do corpo forjada sempre no encontro com o outro, a partir da sexualidade infantil.

Abordar o tema do corpo em psicanálise nos conduz novamenteao texto de Freud Três ensaios sobre sexualidade, de 1905. Nesse texto, o tema do corpo e o da sexualidade se entrelaçam, o corpo enquanto marca do pulsional, investido de energia libidinal, constitui-se como erógeno.

Freud utiliza o conceito de libido para se referir à energia de ordem sexual que impulsiona e investe o corpo. Envolve tanto a necessidadequanto a satisfação, o desejo e o prazer. Para Chemama (1995), a libido é conceituada como a "energia psíquica das pulsões sexuais, que encontram seu regime em termos de desejo, de aspirações amorosas, e que, para S. Freud, explicam a presença e a manifestação do sexual na vida psíquica" (p. 126). Nesse sentido, a libido é o impulso que move o sujeito em direção à satisfação, energia essa que é distribuída nas distintas regiões corporais, as zonas erógenas, ou seja, “(...) uma parte da pele ou da membrana mucosa em que os estímulos de determinada espécie evocam uma sensação de prazer possuidora de uma qualidade particular" (Freud, 1905/1987, p. 188).

Freud nomeia de zona erógena o órgão ou região do corpo cuja excitação adquire caráter sexual. A erogeneidade pode se ligar a algumas partes do corpo de forma mais marcante do que outras, justamente a partir da história relacional com o Outro constituinte. Precisamente, a pele e as mucosas já indicam a importância das zonas de borda, aquelas que não estão nem dentro nem fora, mas em um entre interior-exterior. Para Freud (1905/1987), a exterioridade habita o mundo interno, tanto impulsionada por forças oriundas do interior como do exterior. Os orifícios corporais, ouvido, boca, ânus, olhos também se oferecem como zonas erógenas privilegiadas de borda, indicando como, na história da sexualidade de um sujeito, elas serão protagonistas do encontro com o outro. O corpo é,então, resultado das relações estabelecidas com o outro, o qual irá atribuir sentidos ao organismo, resultando no corpo erógeno. Como nos lembra Voltolini (2008, p. 8), o “corpo do homem estará marcado para sempre, a partir daí por um certo 'em relação à', 'assim me vejo e te vejo segundo a forma pela qual fui visto"'.

Já a pulsão funcionaria como um motor, uma pressão que, posta a trabalhar, geraria o psíquico, originando-se no organismo e se direcionando à busca por algum objeto que possibilite a satisfação (Cherix, 2015). Freud (1905/1987) a nomeia como sendo o "representante psíquico de uma fonte endossomática e contínua de excitação em contraste com um 'estímulo', que é estabelecido por excitações simples vindas de fora” (p. 171), situando-a na fronteira entre o físico e o psíquico.

Se, então, o corpo para a psicanálise é o palco da história dos investimentos libidinais do e no sujeito, onde o pulsional traz a marca desse nem dentro e nem fora que nos constitui na relação com o outro, como será possível ao educador encontrar formas de observar essa história e construir uma trama de sentidos potente para a relação de transmissão? 


\section{Alteridade e educação}

Cabe interrogarmos a relação estabelecida entre professores e alunos na escola, considerando que, nesse contexto, as particularidades das relações com o outro são colocadas em cena constantemente.Freud (1912/1987), ao postular o amor de transferência, indica como essas relações são enganosas, no sentido de que a relação com o outro se dá a partir de clichês já vividos, em uma espécie de reedição e não em um encontro absoluto entre dois. Porém, esse amor reeditado, ainda que de certa forma enganoso, pode se atualizar e se transformar a partir dos encontros e desencontros amorosos que vão ocorrendo ao longo da vida. Como bem fala Voltolini (2006) sobre a transferência na relação professor-aluno, trata-se de um engodo vital, fundamental para que o sujeito se sinta engajado e possa construir laço. O professor estaria condenado a fazer o cálculo desse encontro/desencontro apenas com os elementos que deduz do outro, sabendo que essas impressões se baseiam no próprio já vivido do professor.

Sendo o campo da sexualidade sempre traumático, no sentido de que é nele que o excessivo da força se impõe, ele convoca o adulto educador a lidar com tensões que o interpelam enquanto sujeito. Ou, ainda, os impactos da corporeidade infantil nas relações entre professores e alunos jamais serão neutros, pois o mal-estar relativo ao corpo infantil se produz justamente na evocação da própria sexualidade infantil do adulto.

Relacionando a questão da alteridade à força pulsional, como nos propõe Cardoso (2007, citando Reis, 2004), constituiria, ela mesma, uma diferença, uma exterioridade em relação ao eu. O excesso pulsional podendo produzir o traumático, levando o sujeito a colocar fora de si os elementos intraduzíveis. A questão importante aqui é que esse fora retorna, como uma repetição. Ou seja, a estranheza é inquietante justamente porque ela se faz presente novamente às expensas do trabalho de a manter afastada, significando que o não familiar pode sempre assolar o familiar.

Diante daquilo que aponta para a divisão constitutiva (estranho/familiar) gerando mal-estar, direções diferentes podem ser pensadas. Uma delas seria no sentido da máxima freudiana “onde era o isso, o eu há de advir", significando que um trabalho de trazer parcialmente para dentro o que estava fora, em uma elaboração, pode acontecer. Nesse caso, o inquietante diante da diferença poderia ser motor para uma certa apropriação do eu, a diferença não seria predominantemente negada, mas serviria como operador de significação. Nesse caso, o inominável e sem sentido do traumático poderia ser parcialmente transformado em signo pela linguagem. De outra forma, o eupode peremptoriamente erigir e reforçar defesas contra o estranho inimigo, negando sua familiaridade com a estranheza. $\mathrm{Na}$ acepção psicanalítica, não escapamos de nossa divisão constituinte, onde a estranheza inconsciente sempre poderá ameaçar a organização e estabilidade do eu. Assim, é de mais de um eu provisório e constantemente ameaçado que falamos.

No texto Uma dificuldade no caminho da psicanálise (1917/1987), Freud aborda os três golpes narcísicos sofridos pela humanidade, sendo um deles a descoberta de que o "eu não é o senhor em sua própria casa". O suposto controle do sujeito sobre ideias e ações passa a ser questionado, a partir das descobertas freudianas. Ao propor a existência do inconsciente, através da teoria da libido e das pulsões como propulsoras da vida psíquica, Freud (1917/1987) aponta para forças não passíveis de total dominação pela instância do eu, as quais impulsionam o 
sujeito na busca pela satisfação. Nesse sentido, a condição da onipotência humana é abalada, pois constata-se que as ideias, pensamentos e ações do sujeito não dependem apenas de elementos já conhecidos. Ou seja, com essa descoberta, Freud nos alerta sobre a sobredeterminação na vida psíquica. Segundo Freud, o psiquismo não é uma estrutura simples, caracterizando-se como "um labirinto de impulsos que se esforçam, independentemente um do outro, no sentido da ação (...) muitos dos quais antagônicos e incompatíveis” (p. 175-176). Em determinadas situações, alguns pensamentos resistem ao domínio da vontade, do pensamento lógico e do senso de realidade: "os impulsos surgem, parecendo como que os de um estranho, de modo que o ego (eu) os rejeita; mas ainda assim, os teme e toma precauções contra eles" (p. 176).

No texto $O$ estranho (1919/1987), Freud nos alerta sobre o estranhamento representado pelo outro, o semelhante, como sendo o deslocamento de algo da ordem do recalque que fíca localizado fora do sujeito, no outro. Refere-se ao estranho-familiar, o outro como depositário de tudo o que ficou afastado do eu pelo processo de recalque. O estranho é assim definido por Freud: "Dois conjuntos de ideias que, sem serem contraditórios, ainda são muito diferentes: por um lado, significa o que é familiar e agradável; e, por outro, o que está oculto e se mantém fora da visão" (p. 282). O familiar-recalcado podendo retornar de forma assustadora, produzindo mal-estar e angústia.

Estendendo essa reflexão às relações no contexto escolar, podemos pensar o aluno como representante desse outro que apresenta características e reações nem sempre passíveis de tradução para o educador. Certos alunos que não correspondem ao esperado podem produzir no professor a ausência de nomeações e, com isso, inquietar, implicando certo mal-estar a sua presença na sala de aula. Tal estranhamento poderá ser produtor de impotência, o eu estar tão investido na defesa que nada pode fazer com a diferença. No entanto, também pode ser produtor de potência, convocando o sujeito na construção de um saber-fazer com o limite, buscando novas formas de significação (Scherer, 2014).

Considerando a imagem do aluno na tela (ou a ausência dela) como sendo a marca do ensino durante a pandemia, cabe interrogar os efeitos desse estranho-familiar que retorna diante do ensino remoto.

Partimos, então, da premissa de que o mal-estar oriundo da impossibilidade de se ter total controle sobre os efeitos das pulsões é marca do humano. Na cena escolar, são muitas as respostas do sujeito-professor diante do controle/descontrole em relação ao que irrompe na sala de aula. Diante desse estranho/estrangeiro que é o universo pulsional, a resposta será construída pelo professor no ir e vir entre professor e aluno, sabendo que esse encontro é sempre faltoso, no sentido de que é impossível uma acoplagem perfeita entre um e outro. Trata-se de uma relação de incompletude e não um encontro que finalmente um manual da certa conduta do professor vai estabelecer. Se, na presença concreta entre os corpos, esse ir e vir será marcado por ritmos, pausas, aceleração e descanso; na tela, esses indícios serão bastante diversos.

\section{O aluno-corpo-estranho, ou os alunos sem corpos?}

Conforme propõe Brun (2007), em seu texto L'inquiétante étrangeté du corps, o corpo pode se tornar repentinamente um estranho perturbador. A autora menciona também a instabilidade como inerente ao processo de apropriação do próprio corpo, sendo que o mesmo não será totalmente recoberto pela representação, algo poderá escapar ao controle. Torna-se um 
“estranho permanente", já que a sexualidade infantil recalcada retorna, produzindo a sensação de estranheza. Um corpo erógeno, pulsional, que não se submete totalmente às leis da cultura, sucumbindo ao inesperado. $\mathrm{O}$ corpo familiar, conhecido pelo sujeito, não é totalmente confiável.

Se relacionarmos à cena escolar, poderíamos interrogar os efeitos desse encontro entre educador e o aluno-corpo, carregando o transbordamento próprio de um corpo que é marcado pelo pulsional, que atualiza o infantil do sujeito, trazendo à tona algo da ordem do recalque. A autora sinaliza paralelamente a potência desse encontro do sujeito com o corpo e suas manifestações, para além dos efeitos de estrangeiridade. Tal encontro pode também proporcionar uma familiarização e apropriação com o infantil de cada um, submetendo-se ao processo de simbolização. Esse apontamento poderia estar relacionado àquelas situações em que o educador aceita lidar com o aluno-corpo que foge ao controle, ao esperado, também presentes no contexto educacional. Aprofundar o questionamento sobre o outro, desconfiar das explicações simplificadas, pode ser um caminho para entendermos que o psíquico percorre meandros bastante complexos. Partir do pressuposto do inconsciente é, então, compreender que a diferença não está apenas no outro, mas refere-se ao próprio desconhecimento que cada um tem para consigo mesmo (Carneiro, 2016).

O aluno-corpo como produtor de estranhamento provoca no adulto certo mal-estar, podendo ensejar as mais diferentes formas de lidar com isso, tantas quantas as singularidades dos educadores. No entanto, é no estranhamento, é no ir e vir entre o estranho e o familiar, em contato com a sexualidade infantil do outro e a sua, que o adulto vai sendo capaz de construir chaves de leitura para aquele encontro de transmissão. Trata-se de uma relação entre corpos, em que o olhar, a voz, o olfato, o tato possuem importância. Discutindo o conceito de variação com Dolto, Nasio $(2008$, p. 17) ressalta que o trabalho da psicanalista de crianças "(...) era questioná-las ali onde eu me sentia questionada por seu comportamento, e ali, onde, sobretudo por intermédio delas, eu me sentia questionada na relação que elas tinham comigo". O trabalho analítico com a criança então “(...) consiste em uma mútua confrontação não apenas dos lugares, mas também das velocidades, dos ritmos e fundamentalmente das imagens do corpo" (Nasio, 2008 , p. 18). Se o trabalho analítico com a criança é muito distinto daquele do professor, é também na confrontação de lugares que o professor vai construindo balizas que possibilitem o laborioso e incerto trabalho de criar laços com o aluno. No entanto, sabemos que essa confrontação de lugares se operacionaliza pela oposição, pela diferença. Na supressão da nitidez dos limites promovida pelo "espaço-tempo tecnológico" (Virilio, 1999, p. 10), o próximo e o distante deixam de ser categorias nítidas de oposição. A referência opositiva perde função para uma maleabilidade quase infinita. Essa lógica de achatamento do tempo e do espaço, na tela, concorre para uma indiferenciação das posições entre o observador e o observado, diminuindo as insígnias que o professor usava para ler aquela situação relacional com o outro.

$\mathrm{O}$ encontro/desencontro entre sujeitos, professores e alunos, são marcados pelos sentidos que o corpo adquire para cada um. Tais encontros permitirão ao docente sentidos próprios, tendo em vista a significação que a sexualidade e o corpo assumem para o sujeito. O corpoaluno-estranho não se refere apenas ao que está fora do professor, a algo que se localiza no aluno, mas concerne também ao professor-sujeito, que pode construir uma leitura que inclua mais, ou menos, certa alteridade.

Os corpos-alunos-estranhos seriam justamente aqueles que, existindo para o professor na imediaticidade e parcialidade do seu campo de visão, apagariam a distância entre observado e 
observante em uma ilusão de supressão da alteridade? Esse achatamento poderia, então, concorrer para anular "o caráter vivo, concreto, imprevisível e improvisado característico do que se passa entre humanos" (Voltolini, 2006, p. 16). Se não há garantia da construção do laço entre professor e aluno, como o educador vai encontrar saídas parciais, mas possíveis, a partir das fragmentadas marcas de leitura oferecidas pela imagem na tela?

Em um sentido bastante diferente do mal-estar produzido entre o estranho/familiar que a sexualidade infantil enseja, parece-nos aquele referido aos alunos sem corpos. Esses últimos, bastante relatados por professores de púberes e adolescentes, são aqueles que não aparecem, nem através da imagem nem da voz. Sem a câmera e o microfone ligados,tornam-se presentes na pura ausência para o educador, que não conseguirá recolher fragmentos de presença. Esses casos, para além da imediaticidade e fragmentação que a imagem tem como características, encarnariam a própria anulação peremptória do corpo pulsional. Essa cena absolutamente solitária, a nosso ver, seria paradigmática daquilo que Birman (2012) e Lebrun (2008) apontaram como um mundo sem outro. Nesse caso, o mal-estar do educador estaria mais relacionado ao que Birman (2012) nomeia de desalento, onde não haveria o apelo e a demanda ao outro. Ensina-se para um vazio, um opaco de tela que não dá sinais de vida.

Se podemos compreender certa dificuldade dos adultos-professores em lidar com o corpo e a sexualidade, pois sabemos dos caminhos corporais que a sexualidade assume ao longo da vida dos sujeitos, muitas vezes desalojando-os de seu lugar de domínio, ainda não sabemos ao certo os efeitos para o adulto educador, e para a relação de transmissão que esses novos não-corpos instauram. Talvez angustiados pela impossibilidade de lançar mão de indícios que permitam nomear a estranheza do novo encontro/desencontro, os educadores estejam vivendo mais acentuadamente a impotência diante de um duplo inquietante onde a alteridade arrisca desaparecer.

\section{À guisa de conclusão}

A pandemia nos tem colocado enormes desafios, sendo um deles o novo formato de ensino não presencial para crianças e adolescentes. Essa modalidade instaura uma diferente presença/ausência dos corpos na cena educativa, questionando profundamente os lugares no tempo e no espaço de professores e alunos. Se a mediação pela imagem na tela não é nova, ela nunca tinha sido exclusiva para crianças e adolescentes como modalidade de ensino. Inaugurouse, então, nesse ano de 2020, uma virtualidade educativa sem precedentes para esse público. Cabe ao adulto educador construir bússolas que assegurem uma orientação razoavelmente segura para conduzir o encontro/desencontro com o aluno. Como as fazer diante de corpos em quejustamente a erogeinidade que os constitui fica predominantemente invisível é um questionamento a se fazer.

Sabendo que a construção de laços entre o professor e o aluno se dará pela transferência, que envolve a sexualidade infantil e o estranho-familiar, questionamos como esse encontro/desencontro pode estar sendo afetado pela mediação da tela. Em um achatamento da distância espaço-tempo, a imagem mais imediata concorreria para uma indiferenciação de lugares, dificultando a distância entre observante e observado e a consequente produção de sentidos daquele que observa - em nossa reflexão, o educador. A alteridade que a estranheza do corpo suscita estaria menos em jogo em uma lógica onde o pulsional não é presumido. $\mathrm{O}$ 
corpo plano e fragmentado que aparece na tela ofereceria, assim, menos indícios de leitura para o outro. Sem o ritmo, o movimento, e a expressividade do corpo do outro, a leitura do espaço do entre dois - mais a linguagem - teria que se fazer de outra forma.

\section{Referências}

Bezerra, F. L. L. e Moreira, W. W. (2013). Corpo e educação: o estado da arte sobre o corpo no processo de ensino aprendizagem. Revista Encontro de Pesquisa em Educação. Uberaba, 1(1), (61-75). Recuperado de http://revistas.uniube.br/index.php/anais/article/view/699/996

Birman, J. (2001)Mal-estar na atualidade: a psicanálise e as novas formas de subjetivação. 3. ed. Rio de Janeiro, RJ: Civilização Brasileira.

Birman, J. (2012). O sujeito na contemporaneidade: espaço, dor e desalento na atualidade. Rio de Janeiro: Civilização Brasileira.

Brun, D. (2007). L'inquiétante étrangeté du corps. Les Cahiers du Centre George

Canguilhem. Editora Universitária da França, 1(1), 113-122. Recuperado de https://www.cairn.info/revue-les-cahiers-du-centre-georges-canguilhem-2007-1-page113.htm

Cardoso, M. R. (2007). A impossível "perda" do outro nos estados limites: explorando as noções de limite e alteridade. In: Psicologia em Revista, Belo Horizonte, 13(2), 325-338. Recuperado de: http://pepsic.bvsalud.org/pdf/per/v13n2/v13n2a08.pdf.

Carneiro, C. (2002). Produção científica: Dissertações e teses UFRJ. (Tese de doutorado, Instituto de Psicologia, Universidade Federal do Rio de Janeiro).

Carneiro, C. (2016). Quem é o outro, o diferente? Reflexões sobre psicanálise e educação. Revista Educação Especial, 29(55), 351-360, Universidade Federal de Santa Maria. doi: https://doi.org/10.5902/1984686X15286.

Chemama, R. (1995). Dicionário de psicanálise. Porto Alegre, RS: Artes Médicas Sul.

Cherix, K. (2015). Corpo e envelhecimento: uma perspectiva psicanalítica. Rev. SBPH, 18 (1), 39-51.Recuperado de: http://pepsic.bvsalud.org/pdf/rsbph/v18n1/v18n1a03.pdf

Coutinho, L. G., Carneiro, C.e Salgueiro, L. M. (2018). Vozes de crianças e adolescentes: o que dizem da escola? Psicologia Escolar e Educacional, 22 (1), 185-193. Recuperado de http://dx.doi.org/10.1590/2175-35392018014739

Dolto, F. \& Nasio, J. D. (2008). A criança de espelho. Rio de Janeiro, RJ: Jorge Zahar.

Fernández, A. (1991). A inteligência aprisionada. Porto Alegre, RS: Artmed.

Freud, S. (1987). Três ensaios sobre a teoria da sexualidade. In S. Freud, Edição Standard Brasileira das Obras Psicológicas Completas de Sigmund Freud.(J. Salomão, trad., Vol.7, pp. 123-252). Rio de Janeiro: Imago. (Trabalho original publicado em 1905). 
Freud, S. (1976). A dinâmica da transferência. In S. Freud, Edição Standard Brasileira das Obras Psicológicas Completas de Sigmund Freud.(J. Salomão, trad., Vol.12, pp. 129- 143). Rio de Janeiro, RJ: Imago. (Trabalho original publicado em 1912).

Freud. S. (1987). Uma dificuldade no caminho da psicanálise. In S. Freud, Edição Standard Brasileira das Obras Psicológicas Completas de Sigmund Freud. (J. Salomão, trad., Vol. 17, pp. 169-179). Rio de Janeiro: Imago,1987. (Trabalho original publicado em 1917).

Freud. S. (1987). O estranho. In S. Freud, Edição Standard Brasileira das Obras Psicológicas Completas de Sigmund Freud. (J. Salomão, trad., Vol. 17, pp. 273-314). Rio de Janeiro, RJ: Imago. (Trabalho original publicado em 1919).

Jameson, F. (1991). Pós-Modernismo - a lógica cultural do capitalismo tardio. São Paulo, SP: Ática.

Lebrun, J. P. (2008). A perversão comum: viver juntos sem outro. Rio de Janeiro, RJ: Companhia de Freud.

Lima, N. L. (2020). Eu não sei se o professor está me olhando: o olhar e a tela. Desidades Revista eletrônica de divulgação científica da infância e juventude, 28, 13-25.

Recuperado de: https://revistas.ufrj.br/index.php/desidades/article/view/40381.

Reis, J. (2020). Palavras para lá da pandemia: cem lados de uma crise. Centro de Estudos

Sociais da Universidade de Coimbra. Recuperado de: https://ces.uc.pt/publicacoes/palavraspandemia/

Rushkoff, D. (1999). Um jogo chamado futuro- como a cultura dos garotos pode nos ensinar aviver na era do caos. Rio de Janeiro, RJ: Revan.

Scherer, L. C. B. (2014). Produção científica: Dissertações e teses da UFRGS, Repositório Digital Lume (Dissertação de Mestrado, Faculdade de Educação, Universidade Federal do Rio Grande do Sul). Recuperado de: www.lume.ufrgs.br/handle/10183/106495.

Soja, E. W. (1993). Geografias Pós-Modernas - a reconfiguração do espaço na teoria social crítica. Rio de Janeiro, RJ: Zahar.

Virilio, P. (1993). O espaço crítico. Rio de Janeiro, RJ: Editora 34.

Voltolini, R. (2008). A relação professor-aluno não existe: corpo e imagem, presença e distância. ETD - Educação Temática Digital. Universidade Estadual de Campinas, 8, 119 139. Doi: https://doi.org/10.20396/etd.v8i0.695.

Revisão gramatical: Mariana Correa das Chagas E-mail:marianachagasred@gmail.com

Recebido em novembro de 2020 - Aceito em fevereiro de 2021. 